\title{
Do Time-Varying Betas Help in Asset Pricing? Evidence from Borsa Istanbul
}

\section{Berk Yayvak, Levent Akdeniz \& Aslihan Altay-Salih}

To cite this article: Berk Yayvak, Levent Akdeniz \& Aslihan Altay-Salih (2015) Do Time-Varying Betas Help in Asset Pricing? Evidence from Borsa Istanbul, Emerging Markets Finance and Trade, 51:4, 747-756, DOI: 10.1080/1540496X.2015.1046346

To link to this article: http://dx.doi.org/10.1080/1540496X.2015.1046346

册Published online: 30 Jun 2015.

Submit your article to this journal $\pi$

WII Article views: 113

Q View related articles $₫$

View Crossmark data $\asymp$

4 Citing articles: 1 View citing articles 


\title{
SYMPOSIUM ARTICLES
}

\section{Do Time-Varying Betas Help in Asset Pricing? Evidence from Borsa Istanbul}

\author{
Berk Yayvak, Levent Akdeniz, and Aslihan Altay-Salih \\ Faculty of Business Administration, Bilkent University, Ankara, Turkey
}

\begin{abstract}
We investigate the time variation in the market risk of industry portfolios of Borsa Istanbul with respect to changes in economic conditions by employing the threshold CAPM. The threshold CAPM defines beta as a function of an underlying economic variable, the threshold variable, to allow beta to change between two different regimes when the threshold variable hits a certain threshold level. We use interest rate, currency basket, real effective currency index, and market volatility as candidates for the threshold variable. We find there is a significant time variation in betas with respect to changes in the currency basket level.
\end{abstract}

KEY WORDS: asset pricing, threshold CAPM, time variation in beta

Over the past few decades, how investors assess the risk of future cash flows of an asset and how much premium they demand for that risk have been the center of attention for researchers in finance. Several models have been revealed to describe how investors measure an asset's risk and associate its expected return with that risk. Among these models, the capital asset pricing model (CAPM) of Black (1972), Lintner (1965), and Sharpe (1964) has been considered a cornerstone of theoretical and empirical finance. The CAPM postulates a stable and linear relationship between an asset's expected return and risk.

The early empirical tests of the model generally support its predictions, but later studies, especially Ball (1978), Banz (1981), Basu (1983), Bhandari (1988), Fama and French (1992), Rosenberg et al. (1985), and Stattman (1980), examine empirical implementations of the model and report that much of the variation in expected return is unrelated to market beta. One of the explanations for the failure of the model is the assumption that beta and market risk premium are constant over time. Since the CAPM is a single-period model assuming that all investors have the same expectations of mean, variance, and covariance of future returns, in the empirical examination of this unconditional model with real-world data, it is necessary to assume that risk measures of investors remain constant over time. However, as stated by Jagannathan and Wang (1996), this is not a reasonable assumption because changes in overall economic conditions might conduce the alteration of the trade-off between risk and expected return. Many other researchers, notably Ferson (1989), Ferson and Harvey (1991, 1993), and Ferson and Korajczyk (1995), also argue market beta and market risk premium vary over time rather than being constant.

Early empirical investigations on time-varying betas (e.g., Blume 1970; Fabozzi and Francis 1978; Sunder 1980) show that market betas appear to be time varying. More recent studies also find evidence for time variation in betas for both developed and emerging countries; for example, Australia (Brooks et al. 1998; Faff et al. 1992), Canada (Episcopos 1996), Hong Kong (Chang 1997), Korea (Bos and Fetherston 1992), the United Kingdom (Reyes 1999), and the United States (Bollerslev et al. 1988; Ferson 1989; Ferson and Harvey 1991, 1993; Ferson and Korajczyk 1995; Jagannathan and Wang 1996).

Despite the considerable number of empirical studies presenting evidence on time variation in betas, there is no consensus on a framework to capture this variation. There are two common approaches to explicitly model time-varying beta with continuous approximations and the theoretical

Address correspondence to Levent Akdeniz, Faculty of Business Administration, Bilkent University, Bilkent, 06800 Ankara, Turkey. E-mail: akdeniz@bilkent.edu.tr 
frame; many of the empirical studies either follow autoregressive conditional heteroskedasticity$(\mathrm{ARCH})$ based approaches to estimate conditional beta or use instrumental variables to proxy time variation in betas and market risk premium.

Empirically documented large pricing errors of conditional CAPMs have prompted researchers to investigate alternative approaches to model time variation in beta, many of which have assumed that betas change discretely over time. As stated by Akdeniz et al. (2003), this assumption yields a nonlinear relationship between risk and expected return, and treating a possible nonlinear relationship as a linear one may lead to serious prediction problems in estimation. Since nonlinear models are inherently more difficult than linear models to interpret, there are only a few nonlinear asset-pricing models in the literature.

Akdeniz et al. (2003) propose a nonlinear version of the conditional CAPM, where they borrow from Hansen's (2000) threshold estimation framework. This is a simple and intuitive version of the conditional CAPM that captures the slow variation by allowing betas to respond to the changes in the economic environment. Unlike the traditional CAPM, the market risk is modeled as a function of an underlying economic variable, which is called threshold variable, in order to procure beta to change between two different beta regimes when the threshold variable reaches a certain threshold level.

The application of nonlinear asset-pricing models in the developed markets generally provides supportive evidence for the existence of discrete changes in market betas. For instance, empirical findings of Abdymomunov and Morley (2011), Akdeniz et al. (2003), Akdeniz et al. (2008), Akdeniz et al. (2011), and Huang (2000) provide strong evidence of discrete variation in betas for developed markets and report the superiority of nonlinear asset pricing models over both unconditional and conditional CAPM.

In this study, we investigate the time variation in betas of nonfinancial firms traded in the Borsa Istanbul over the period January 1998-December 2011 by utilizing the threshold CAPM of Akdeniz et al. (2003). The threshold CAPM defines beta as a function of an underlying economic variable, the threshold variable, to allow beta to change between two different regimes when the threshold variable hits a certain threshold level. To do so, we use monthly observations of interest rates, currency basket, real effective currency index, and market volatility as candidates for the threshold variable. Our findings indicate that there is a significant time variation in betas during the sample period with respect to rate of changes in the currency basket level. Furthermore, comparing the pricing performance of the model with the traditional CAPM via time-series regressions, the threshold CAPM performs better in pricing.

\section{Data}

The data in this study include nonfinancial firms that are traded in the Borsa Istanbul Stock Exchange during the period January 1998-December 2011, with a total of 168 months. This was a period during which local and global financial crises took place, which enables us to analyze the response of betas to the changes in the economic environment. Each year, a firm must be trading in BIST for both June of year $t$ and December of year $t-1$ to be included in our data. The number of firms that meet these requirements ranges from a minimum of 150 in 1998 to a maximum of 227 in 2011.

We obtained the adjusted monthly closing prices of each stock and the levels of value-weighted BIST 100 index from DataStream. Since all prices are adjusted for stock splits and dividends, monthly returns are calculated as the percentage change. We use interest rates of treasury auctions from the database of Ministry of Development for the risk-free rate.

\section{Threshold Variables}

As stated by Harvey (2001), the evidence of time variation in betas can be highly sensitive to the choice of instrumental variables. Considering the variables suggested in the literature as predicting stock returns, four instrumental variables are selected as candidates for the threshold variable of the model. These variables are risk-free interest rate, rate of change in the currency basket level, rate of change in the real effective currency index, and historical volatility of the BIST-100 index. 
Table 1. Descriptive statistics for chosen candidates of the threshold variable

\begin{tabular}{lccccc}
\hline & Mean (percent) & Median (percent) & Maximum (percent) & Minimum (percent) & Standard deviation (percent) \\
\hline $\mathrm{RF}$ & 2.74 & 1.70 & 9.40 & 0.62 & 2.12 \\
$\mathrm{CB}$ & 1.91 & 0.91 & 22.75 & -7.27 & 4.91 \\
$\mathrm{Cl}$ & 0.23 & 0.45 & 14.50 & -14.68 & 3.60 \\
$\mathrm{HV}$ & 12.76 & 10.61 & 29.12 & 5.44 & 6.04
\end{tabular}

Notes: $R F$ is the monthly risk-free rate; $C B$ is the monthly percentage change in the currency basket; $C I$ is the monthly percentage change in the real effective currency index; $H V$ is the monthly historical volatility of the BIST-100.

Akdeniz et al. (2003) show that interest rate signals a regime shift in betas strongly when compared to other threshold variables in their study. Bansal and Viswanathan (1993) document similar evidence for nonlinearity of returns due to market risk and interest rates. Considering the high volatility of interest rates during the crisis periods in Turkey, we believe that changes in interest rates may trigger a variation in market betas.

The foreign currency basket consisting of U.S. dollar to Turkish lira (TL) and euro to TL exchange rates with equal weights is also selected as a candidate for the threshold variable since it is considered as a good proxy for currency risk. Chkili et al. (2011) reports a significant relationship between currency basket and stock returns. We consider the real effective currency index, calculated and reported by the Central Bank of Turkey, as the third candidate for the threshold variable. The index is generated by deflating a portfolio of thirty-six countries' effective currency ratios weighted by Turkey's foreign trade volume with these countries. ${ }^{1}$

Finally, we use the volatility of market portfolio as the fourth candidate for the threshold variable. Adrian and Rosenberg (2008), Akdeniz et al. (2011), and Ang et al. (2006) suggest volatility as a variable in predicting stock returns.

Table 1 presents descriptive statistics for four candidates for the threshold variable. As can be seen in the table, the Turkish financial environment exhibits typical emerging market characteristics with relatively higher rates of return and volatility.

\section{The Industry Portfolios}

We form value-weighted industry portfolios for each month from January 1998 until December 2011. Table 2 provides the names of thirteen industry portfolios formed according to the industry index codes of Borsa Istanbul. The Industry portfolio of education, health, sports, and other social services is excluded from the sample since there are only a few companies traded over the sample period.

Table 3 presents descriptive statistics for monthly industry and market returns. The monthly mean returns have a wide range across industries. For instance, the lowest mean is 0.50 percent, and the highest mean is 4.05 percent, while the market mean return is 2.54 percent. The standard deviations of the returns on the portfolios are quite high, reaching up to 20.26 percent, while the standard deviation of the market returns is 14.22 percent. The correlation coefficients of returns on industry portfolios with the market returns have a range from 67 to 94 percent. The lowest coefficient is for the industry of electricity, gas, and water; therefore, the relationship of this industry with the market portfolio is slightly low when compared to other industry portfolios.

\section{Fama-French SMB and HML Factors}

To compare the performance of threshold CAPM with the Fama-French three-factor model (Fama and French 1993), we need to construct the small-minus-big (SMB) and high-minus-low (HML) factors for the Turkish stock market during our study period. ${ }^{2}$ 
Table 2. List of industry portfolios

\begin{tabular}{ll}
\hline Portfolio & \\
\hline Portfolio 1 & Nonmetallic mineral products \\
Portfolio 2 & Basic metal industry \\
Portfolio 3 & Fabricated metal products, machinery, and equipment \\
Portfolio 4 & Food, beverage, and tobacco \\
Portfolio 5 & Textile \\
Portfolio 6 & Paper and paper products, printing and publishing \\
Portfolio 7 & Chemicals, petroleum, rubber, and plastic products \\
Portfolio 8 & Tourism \\
Portfolio 9 & Wholesale and retail trade \\
Portfolio 10 & Transportation, telecommunication, and storage \\
Portfolio 11 & Electricity, gas, and water \\
Portfolio 12 & Construction \\
Portfolio 13 & Technology
\end{tabular}

Notes: This table reports the names of the industries in accordance with the industry indexes of the Borsa Istanbul Stock Exchange. The study covers stocks trading in the BIST over the period January 1998-December 2011.

Table 3. Descriptive statistics for percentage monthly returns on the market portfolio and industry portfolios

\begin{tabular}{lcrrccc}
\hline & Mean & Median & Maximum & Minimum & Standard deviation & Correlation (percent) \\
\hline Market portfolio & 2.54 & 2.35 & 79.78 & -39.03 & 14.22 & \\
Portfolio 1 & 2.45 & 3.35 & 65.89 & -39.65 & 11.97 & 86.93 \\
Portfolio 2 & 2.94 & 2.68 & 62.34 & -41.01 & 15.13 & 83.55 \\
Portfolio 3 & 2.67 & 1.22 & 84.46 & -42.04 & 15.59 & 93.71 \\
Portfolio 4 & 2.96 & 2.10 & 69.64 & -34.76 & 12.69 & 81.83 \\
Portfolio 5 & 2.05 & 1.10 & 67.99 & -43.17 & 13.45 & 82.75 \\
Portfolio 6 & 2.32 & 2.45 & 71.70 & -41.37 & 15.00 & 83.60 \\
Portfolio 7 & 2.41 & 2.32 & 72.83 & -42.91 & 13.38 & 90.13 \\
Portfolio 8 & 2.26 & -0.24 & 93.97 & -56.04 & 20.26 & 72.95 \\
Portfolio 9 & 2.66 & 2.67 & 62.94 & -34.74 & 12.17 & 85.46 \\
Portfolio 10 & 3.21 & 0.29 & 127.03 & -37.71 & 19.11 & 79.96 \\
Portfolio 11 & 0.50 & 0.01 & 73.82 & -45.08 & 13.96 & 66.85 \\
Portfolio 12 & 4.05 & 3.20 & 66.04 & -47.61 & 15.46 & 73.19 \\
Portfolio 13 & 3.01 & 1.48 & 111.53 & -43.83 & 19.56 & 87.22
\end{tabular}

Notes: All values are given in percentages. The market portfolio is the National 100 Market Index (BIST-100). The last column presents the correlation coefficients of the industry portfolio returns with the market returns.

To do so, we form six portfolios using two-pass sorts with respect to market capitalization (size) and book-to-market (BE/ME) ratio. Stocks are first sorted by size for each year and divided into two groups called small (S) and big (B). Then each group is subdivided into three BE/ME groups where the stocks within the 30 percent lowest $\mathrm{BE} / \mathrm{ME}$ ratio are called low (L); the stocks within the 30 percent highest $\mathrm{BE} /$ $\mathrm{ME}$ ratio are called high $(\mathrm{H})$; and the remaining stocks are called medium $(\mathrm{M})$. As a result, six portfolios $(\mathrm{S} / \mathrm{L}, \mathrm{S} / \mathrm{M}, \mathrm{S} / \mathrm{H}, \mathrm{B} / \mathrm{L}, \mathrm{B} / \mathrm{M}, \mathrm{B} / \mathrm{H})$ are formed with respect to size and $\mathrm{BE} / \mathrm{ME}$. The SMB factor is constructed by taking the difference between the average return on three small portfolios and the average return on three big portfolios for each year. Similarly, the HML factor is constructed by taking the difference between the average return on two high and the average return on two low portfolios. 


\section{Methodology}

\section{Threshold CAPM}

There is now considerable empirical evidence on time variation in betas since relative risk of a firm's cash flow is likely to vary over time. However, it is not clear how this variation should be captured. Many researchers (see Ferson and Harvey 1993; Jagannathan and Wang 1996) model the variation in betas using continuous approximation and the theoretical framework of the conditional CAPM. However, Ghysels (1998) shows that this approximation fails to capture the time series dynamics of beta. We argue that modeling the market risk as a function of a variable that allows betas to respond to the movements in the economic activity, when a certain threshold is reached, may be a good approximation to capture the time variation in betas.

Akdeniz et al. (2003) suggest a version of CAPM, threshold CAPM, and formulate time-varying beta as a function of an underlying variable by using an indicator function to allow beta to change discretely between two regimes:

$$
\mathrm{r}_{\mathrm{t}+1}=\left(\beta_{1} 1_{\left\{\mathrm{z}_{\mathrm{t}} \leq \lambda\right\}}+\beta_{2} 1_{\left\{\mathrm{z}_{\mathrm{t}}>\lambda\right\}}\right) \mathrm{rm}_{\mathrm{t}+1}+\mathrm{e}_{\mathrm{t}+1},
$$

where $\beta_{t}$ is the parameterized time-varying beta; $r m_{t+1}$ represents the excess return from $t$ to $t+1$ on the market portfolio; $r_{t+1}$ is the excess return on any asset or portfolio of assets; $Z_{t}$ is the threshold variable; $1_{\{\}}$is the indicator function, and $\lambda$ is the parameter for the underlying economic variable.

We investigate the existence of time variation in the relationship between market risk and expected return by testing for a threshold effect. We employ the heteroskedasticity-consistent Lagrange multiplier (LM) test of Hansen (1996).

We can rewrite Equation (1) in the following form:

$$
r_{t+1}=\theta^{\prime} x_{t+1}+\delta^{\prime} x_{t+1}(\lambda)+e_{t+1}
$$

where $x_{t+1}=r m_{t+1} ; x_{t+1}(\lambda)=x_{t+1} 1_{\left\{z_{t} \leq \lambda\right\}} ; \theta=\beta_{2}$, and $\delta=\beta_{1}-\beta_{2}$.

The null hypothesis of no significant regime shifts in portfolio betas due to changes in the level of threshold parameter, $\mathrm{H}_{0}: \delta=0$, is tested against $\mathrm{H}_{1}: \delta \neq 0$. For all $\lambda \in \Gamma$ we have the following LM statistics for the null of no threshold.

$$
\begin{aligned}
& L M_{T}(\lambda)=T[R \hat{\gamma}(\lambda)]^{\prime}\left[R \hat{V}_{T}^{*}(\lambda) R^{\prime}\right]^{-1}[R \hat{\gamma}(\lambda)] \\
& \text { where } R=[0, I], \hat{\gamma}(\lambda)=\left[\hat{\theta}(\lambda)^{\prime}, \hat{\delta}(\lambda)^{\prime}\right]^{\prime} \\
& \hat{\gamma}(\lambda)=\left[\sum_{t=1}^{T} x_{t+1}^{*}(\lambda) x_{t+1}^{*}(\lambda)^{\prime}\right]^{-1}\left[\sum_{t=1}^{T} x_{t+1}^{*}(\lambda) r_{t+1}\right] \\
& \mathrm{x}_{\mathrm{t+1}}^{*}(\lambda)=\left[x_{t+1}, x_{t+1}(\lambda)\right] \\
& \hat{\mathrm{V}}_{\mathrm{T}}^{*}(\lambda)=M_{T}(\lambda)^{-1} \tilde{V}_{T}(\lambda) M_{T}(\lambda)^{-1} \\
& \mathrm{M}_{\mathrm{T}}(\lambda)=\frac{1}{T} \sum_{t=1}^{T} x_{t+1}^{*}(\lambda) x_{t+1}^{*}(\lambda)^{\prime} \\
& \tilde{\mathrm{V}}_{\mathrm{T}}(\lambda)=\frac{1}{T} \sum_{t=1}^{T} x_{t+1}^{*}(\lambda) x_{t+1}^{*}(\lambda)^{\prime} \tilde{e}_{t+1}{ }^{2}
\end{aligned}
$$

The $e_{t}$ is obtained from the restricted least squares. Unfortunately, the large sample limit for the supLM test is not nuisance free since the threshold is not identified under the null of no threshold effect. Hansen (1996) suggests a bootstrap analog of the sup-LM test. Hansen (1996) shows that this bootstrap method yields asymptotically correct $p$-values. ${ }^{3}$ 
Table 4. Bootstrap $p$-values for industry portfolios

\begin{tabular}{lllll}
\hline & RF & CB & CI & HV \\
\hline Portfolio 1 & 0.057 & 0.012 & 0.091 & 0.013 \\
Portfolio 2 & 0.041 & 0.008 & 0.016 & 0.056 \\
Portfolio 3 & 0.005 & 0.031 & 0.493 & 0.124 \\
Portfolio 4 & 0.779 & 0.000 & 0.494 & 0.254 \\
Portfolio 5 & 0.072 & 0.006 & 0.455 & 0.037 \\
Portfolio 6 & 0.062 & 0.278 & 0.016 & 0.188 \\
Portfolio 7 & 0.083 & 0.016 & 0.030 & 0.026 \\
Portfolio 8 & 0.568 & 0.008 & 0.231 & 0.217 \\
Portfolio 9 & 0.009 & 0.001 & 0.049 & 0.075 \\
Portfolio 10 & 0.000 & 0.059 & 0.356 \\
Portfolio 11 & 0.206 & 0.028 & 0.036 & 0.338 \\
Portfolio 12 & 0.184 & 0.000 & 0.099 & 0.069 \\
Portfolio 13 & 0.007 & 0.075 & 0.739 & 0.115
\end{tabular}

Notes: The bootstrap $p$-values are calculated from modified sup-LM test by following the steps outlined by Hansen (1996). The candidate threshold variables are the monthly risk-free rate (RF), the monthly rate of change in the currency basket $(\mathrm{CB})$, the monthly rate of change in the real effective currency index (CI), and the historical volatility of the BIST-100 (HV).

Table 4 reports the bootstrap $p$-values for the sup-LM test for industry portfolios. As can be seen, monthly rate of change in the currency basket (CB) signals a regime shift in betas for twelve of thirteen industry portfolios at 10 percent or below significance levels. Eight of thirteen industry portfolios exhibit statistically significant regime shifts in betas with respect to interest rates (RF) and real effective currency index (CI) at 10 percent or below significance levels. A smaller number of industry portfolios show significant variation between betas and other threshold candidates such as historical volatility. Therefore, changes in the currency basket dominate other variables as a threshold candidate. We choose monthly rate of change in the currency basket as the threshold variable for the threshold CAPM since our findings suggest that investors seem to update their beta estimates with respect to the changes in the currency basket level.

\section{Results}

The threshold CAPM is a simple and intuitive nonlinear model. It captures the slow variation in betas and allows betas to respond to the changes in the economic environment. In light of the findings in the previous section, we model the market risk as a function of the rate of change in the currency basket. The model allows beta to change when the rate of change in the currency basket hits a certain threshold level; thus, it allows for two different beta regimes. To capture the slowly changing nature of market risk, threshold CAPM treats beta as constant for certain ranges of the threshold variable. This way of modeling the dynamics of beta is a good approximation for a slowly changing continuous beta.

Table 5 reports the static CAPM betas, the threshold CAPM betas in two regimes, and the threshold estimate of the currency basket for the industry portfolios. We do not report threshold CAPM betas and associated threshold estimates for portfolios with an insignificant bootstrap $p$-value for the threshold variable. As can be seen in the first column, the betas from the static CAPM are below one for most of the portfolios. This is probably because firms with higher beta values are mostly financial firms in the BIST 100 index, which are excluded from the sample.

The second and third columns report threshold CAPM betas for the two regimes, and the fourth column reports the associated threshold estimate for the rate of change in the currency basket. For example, the portfolio of the basic metal industry (Portfolio 2) is less risky with a beta of 0.6501 when 
Table 5. Unconditional CAPM betas, threshold CAPM betas, and threshold estimates of rate of change in the currency basket level for industry portfolios

\begin{tabular}{lcccc}
\hline & $\boldsymbol{\beta}_{\text {CAPM }}$ & $\boldsymbol{\beta}_{\text {Regime 1 }}$ & $\boldsymbol{\beta}_{\text {Regime 2 }}$ & Threshold estimate \\
\hline Portfolio 1 & 0.7276 & 0.9221 & 0.7174 & -0.0411 \\
Portfolio 2 & 0.8922 & 0.6501 & 0.9171 & -0.0023 \\
Portfolio 3 & 1.0247 & 0.9759 & 1.0494 & -0.0050 \\
Portfolio 4 & 0.7257 & 0.6909 & 1.0743 & 0.1359 \\
Portfolio 5 & 0.7910 & 0.6478 & 0.8958 & 0.0429 \\
Portfolio 6 & 0.8782 & - & - & - \\
Portfolio 7 & 0.8445 & 0.5110 & 0.8543 & -0.0499 \\
Portfolio 8 & 1.0421 & 1.0762 & 0.8464 & 0.1383 \\
Portfolio 9 & 0.7310 & 0.5681 & 0.7692 & -0.0050 \\
Portfolio 10 & 1.0676 & 0.8849 & 1.2817 & 0.0449 \\
Portfolio 11 & 0.6611 & 0.6013 & 1.2295 & 0.1119 \\
Portfolio 12 & 0.7891 & 0.5896 & 0.9130 & 0.0358 \\
Portfolio 13 & 1.2047 & 1.0069 & 1.3917 & 0.0449
\end{tabular}

Notes: Regime 1 (2) corresponds to lower (higher) rate of changes in currency basket than the threshold estimate. The BIST-100 index is used as a market portfolio, and the sample includes the adjusted monthly returns on industry portfolios over the period January 1998-December 2011. Threshold betas and associated threshold estimates are not reported for portfolios that do not possess a threshold effect.

the rate of change in the currency basket level is below -0.23 percent; however, it gets riskier with a beta value of 0.9171 when rate of change in the currency basket level exceeds -0.23 percent. As can be seen in Table 5, industries' market risks respond differently to the appreciation of local currency. For example, when the appreciation in foreign currency is above a threshold level, Industry 4 (food, beverage, and tobacco), Industry 5 (textile), Industry 10 (transportation, telecommunication, and storage), Industry 11 (electricity, gas, and water), Industry 12 (construction), and Industry 13 (technology) become riskier with higher betas. These findings are intuitive because high monthly appreciation in foreign currency leads to deteriorating conditions in businesses with higher imported raw material costs and lower domestic demand; thus, those industries get riskier. Moreover, this finding is also meaningful for Turkey since Turkey suffers from a significant current account deficit. Thus, those industries that contribute to the negative trade balance are more sensitive to the changes in foreign exchange rates. Industry 8 (tourism) gets less risky when the appreciation of foreign currency exceeds the threshold level (13 percent). The tourism sector in Turkey benefits from appreciation of foreign currency since package prices get relatively cheaper for foreigners; thus this sector is able attract more foreign demand. Literature reports similar findings that investors do care about fluctuations in exchange rates while investing in stocks in emerging markets (see Adler and Dumas 1984; De Santis and Gérard 1998; De Santis et al. 2003; Jorion 1990).

\section{Pricing Errors}

The documented evidence indicates that portfolio betas shift significantly between two regimes when rate of change in the currency basket is used as the threshold variable. To measure the economic value of the improvement gained, we compare pricing errors of the threshold CAPM with static CAPM and Fama-French three-factor model by using root mean squared error (RMSE) measure. We use the following formula to calculate RMSE:

$$
R M S E=\sqrt{\frac{1}{T} \sum_{t}^{T}\left(r_{i, t}-\widehat{r}_{i, t}\right)^{2}},
$$


Table 6. RMSE pricing errors for the static CAPM, the threshold CAPM, and the Fama-French three-factor model on industry portfolios

\begin{tabular}{lccc}
\hline & Static CAPM & Threshold CAPM & Three-factor model \\
\hline Portfolio 1 & 0.0588 & 0.0586 & 0.0587 \\
Portfolio 2 & 0.0830 & 0.0829 & 0.0828 \\
Portfolio 3 & 0.0543 & 0.0541 & 0.0534 \\
Portfolio 4 & 0.0725 & 0.0716 & 0.0706 \\
Portfolio 5 & 0.0758 & 0.0738 & 0.0651 \\
Portfolio 6 & 0.0820 & - & 0.0791 \\
Portfolio 7 & 0.0577 & 0.0570 & 0.0567 \\
Portfolio 8 & 0.1381 & 0.1375 & 0.1322 \\
Portfolio 9 & 0.0632 & 0.0623 & 0.0622 \\
Portfolio 10 & 0.1145 & 0.1120 & 0.1136 \\
Portfolio 11 & 0.1036 & 0.1039 \\
Portfolio 12 & 0.1040 & 0.1039 & 0.1043 \\
Portfolio 13 & 0.1049 & 0.0916 & 0.0949
\end{tabular}

Note: Pricing errors for the threshold CAPM are not reported for portfolios that do not exhibit a significant threshold effect.

where $r_{i, t}$ is the return on a portfolio at time $t$, and $\widehat{r}_{i, t}$ is the estimate out of static CAPM, threshold CAPM, and Fama-French three-factor model.

Table 6 reports associated pricing errors for the industry portfolios. As can be seen in the table, threshold CAPM produces lower pricing errors in all industries when compared to the static CAPM. Annual difference in pricing errors between static CAPM and threshold CAPM ranges between 0.12 percent and 4.4 percent. For example, the improvement in pricing error is 4.4 percent in Industry 13 in yearly terms, which is an economically significant difference for portfolio performances. Therefore, we can conclude that the threshold CAPM outperforms the static CAPM. The FamaFrench three-factor model yields similar pricing errors compared to the threshold CAPM. In seven of twelve portfolios, the three-factor model exhibits lower pricing errors relative to threshold CAPM. Three-factor model has been criticized for not linking its factors to the economically relevant risk factors. Our results are important in the sense that threshold CAPM performance is similar to the performance of the three-factor model by only capturing the time variation in beta with respect to an economically intuitive threshold variable. This study strictly resides in a CAPM world; therefore, higher order of moments of the return distribution is ignored. However, there are studies that show that higher order moments might be relevant in pricing risky assets (See Atilgan and Demirtas 2013a, 2013b; Bali et al. 2009).

\section{Conclusion}

We analyze the performance of the threshold CAPM of Akdeniz et al. (2003) using industry portfolios constructed from stocks trading in Borsa Istanbul during the period 1998-2011. We show that there is significant time variation in market risk of industry portfolios with respect to monthly rate of changes in the currency basket. Dynamics of time variation differ across industry specifications. While some industries switch to a higher market risk level when the Turkish lira depreciates, others switch to lower risk levels at different threshold levels. In particular, industries whose profitability is positively related to the foreign exchange rate's appreciation get less risky during times of rises in the currency basket level. 
We report that the threshold CAPM outperforms the static CAPM since it produces lower pricing errors. The Fama-French three-factor model yields similar pricing errors compared to the threshold CAPM. The three-factor model has been criticized for not linking its factors to the economically relevant risk factors. Our results are important in the sense that threshold CAPM performance is similar to the performance of the three-factor model by only capturing the time variation in Beta with respect to an economically intuitive threshold variable. Note that the threshold CAPM is still a one-factor model and hence comparing it to a multifactor model already puts the static model at a disadvantage.

The findings of this study have important implications for both portfolio managers and investors who are performing asset allocation, portfolio selection, and hedging decisions in Turkish markets. In addition, the knowledge of dynamics of time-varying betas could contribute to dynamic strategies for hedging.

For future research, alternative nonlinear approaches, notably multiregime threshold models and Markov-switching frameworks, could be utilized to model time variation in market risk.

\section{Notes}

1. For a more detailed description, see Saygili et al. (2010).

2. Although recent studies employ the four-factor model including the momentum factors, we did not do so because we wanted to compare our findings with the findings of earlier studies conducted in developed markets.

3. See Akdeniz et al. (2003) for the details of bootstrap analog.

\section{References}

Adler, M., and B. Dumas. 1984. "Exposure to Currency Risk: Definition and Measurement." Financial Management 13: 41-50. Adrian, T., and J. Rosenberg. 2008. "Stock Returns and Volatility: Pricing the Short-Run and Long-Run Components of Market Risk.” Journal of Finance 63, no. 6: 2997-3030.

Akdeniz, L.; A. Altay-Salih; and M. Caner. 2003. "Time Varying Betas Help in Asset Pricing: The Threshold CAPM.” Studies in Nonlinear Dynamics and Econometrics 6: 1-16.

Akdeniz, L.; A. Altay-Salih; and Y. E. Arısoy. 2011. “Aggregate Volatility and Threshold CAPM.” Working Paper, Bilkent University, Ankara.

Akdeniz, L., and W.D. Dechert. 2008. “The Equity Premium in Brock's Asset Pricing Model.” Journal of Economic Dynamics and Control 31:2263-2292.

Ang, A.; R.J. Hodrick; Y. Xing; and X. Zhang. 2006. "The Cross-Section of Volatility and Expected Stock Returns" Journal of Finance 61, no. 1: 259-297.

Atilgan, Y., and K.O. Demirtas. 2013a. "Downside Risk in Emerging Markets.” Emerging Markets Finance and Trade 49, no. 3: 64-83.

. 2013b. "Reward to Risk Ratios in Financial Markets." Iktisat Isletme ve Finans 28: 9-32.

Bali, T.G.; K.O. Demirtas; and H. Levy. 2009. "Is There an Intertemporal Relation Between Downside Risk and Expected Returns?" Journal of Financial and Quantitative Analysis 44, no. 4: 883-909.

Ball, R. 1978. "Anomalies in Relationships Between Securities' Yields and Yield-Surrogates.” Journal of Financial Economics 6: 103-126.

Bansal, R., and S. Viswanathan. 1993. "No Arbitrage and Arbitrage Pricing: A New Approach.” Journal of Finance 48, no. 4:1231-1262.

Banz, R.W. 1981. "The Relationship Between Return and Market Value of Common Stocks.” Journal of Financial Economics 9 , no. 1: $3-18$.

Basu, S. 1983. "The Relationship Between Earnings Yield, Market Value and Return for NYSE Common-Stocks: Further Evidence.” Journal of Financial Economics 12, no. 1: 129-156.

Bhandari, L.C. 1988. "Debt/Equity Ratio and Expected Common Stock Returns: Empirical Evidence.” Journal of Finance 43, no. 2: $507-528$.

Black, F. 1972. "Capital Market Equilibrium with Restricted Borrowing.” Journal of Business 45: 444-455.

Blume, M. 1970. "Portfolio Theory: A Step Towards Its Practical Application.” Journal of Business 43, no. 2: $152-173$.

Bollerslev, T.; R.F. Engle; and J.M. Wooldridge. 1988. "A Capital Asset Pricing Model with Time-Varying Covariances." Journal of Political Economy 96: 116-131.

Bos, T., and T.A. Fetherston. 1992. "The Anticipation and Impact of Intermediate Credit Reappraisals on Bond Substitution Swaps." Journal of Finance Strategic Decisions 5, no. 3: 19-38.

Brooks, R.; R. Faff; and M. McKenzie. 1998. "Time-Varying Beta Risk of Australian Industry Portfolios: A Comparison of Modeling Techniques.” Australian Journal of Management 23: 1-22.

Cheng, J.W. 1997. "A Switching Regression Approach to the Stationarity of Systematic and Non-systematic Risks: The Hong Kong Experience.” Applied Financial Economics 7: 45-58. 
Chkili, W.; C. Aloui; O. Masood; and J. Fry. 2011. "Stock Market Volatility and Exchange Rates in Emerging Countries: A Markov-State Switching Approach.” Emerging Markets Review 12: 272-292.

De Santis, G., and G. Bruno. 1998. "How Big Is the Premium for Currency Risk?” Journal of Financial Economics 49, no. 3: 375-412.

De Santis, G.; G. Bruno; and P. Hillion 2003. "The Relevance of Currency Risk in the EMU.” Journal of Economics and Business 55, no. 5-6:427-462.

Episcopos, A. 1996. "Stock Return Volatility and Time-Varying Betas in the Toronto Stock Exchange." Quarterly Journal of Business and Economics 35, no. 4: 28-38.

Fabozzi, F., and J. Francis 1978. "Beta as a Random Coefficient." Journal of Financial and Quantitative Analysis. 13: $101-116$.

Faff, R.W.; J.H.H. Lee; and T.R.L. Fry. 1992. "Time Stationarity of Systematic Risk: Some Australian Evidence.” Journal of Business Finance and Accounting 19: 253-270.

Fama, E.F., and K.R. French. 1992. "The Cross-Section of Expected Stock Returns.” Journal of Finance 47, no. 2: 427-465. 1993. "Common Risk Factors in the Returns on Stocks and Bonds." Journal of Financial Economics 33, no. 1: 3-56.

Ferson, W.E. 1989. "Changes in Expected Security Returns, Risk and the Level of Interest Rates." Journal of Finance 44, no. 5: 1191-1214.

Ferson, W.E., and C.R. Harvey. 1991. "The Time Variation of Economic Risk Premiums.” Journal of Political Economy 99: 385-415.

1993. "The Risk and Predictability of International Equity Returns.” Review of Financial Studies 6, no. 3: 527-566.

Ferson, W.E., and R.A. Korajczyk. 1995. "Do Arbitrage Pricing Models Explain the Predictability of Stock Returns?" Journal of Business 68: 309-349.

Ghysels, E. 1998. "On Stable Factor Structures in the Pricing of Risk: Do Time-Varying Betas Help or Hurt?" Journal of Finance 53, no. 2: 549-573.

Hansen, B.E. 1996. "Inference When a Nuisance Parameter Is Not Identified Under the Null Hypothesis." Econometrica 64: 413-430.

2000. "Sample Splitting and Threshold Estimation." Econometrica 68, no. 3: 575-605.

Harvey, C.R. 2001. "The Specification of Conditional Expectations.” Journal of Empirical Finance 8: 573-638.

Huang, H.C. 2000. "Tests of Regimes-Switching CAPM.” Applied Financial Economics 10: 573-578.

Jagannathan, R., and Z.Y. Wang. 1996. "The Conditional CAPM and the Cross-Section of Expected Returns." Journal of Finance 51, no. 1: 3-53.

Jorion, P. 1990. "The Exchange Rate Exposure of U.S. Multinationals.” Journal of Business 63, no. 3: 331-345.

Lintner, J. 1965. "The Valuation of Risk Assets and the Selection of Risky Investments in Stock Portfolios and Capital Budgets." Review of Economics and Statistics 47: 13-37.

Reyes, M.G. 1999. "Size, Time-Varying Beta and Conditional Heteroscedasticity in UK Stock Returns." Review of Financial Economics 8, no. 1: 1-10.

Rosenberg, B.; K. Reid; and R. Lanstein. 1985. "Persuasive Evidence of Market Inefficiency.” Journal of Portfolio Management 11, no. 3: 9-16.

Saygili, H.; M. Saygili; and G. Yilmaz. 2010. "Real Effective Exchange Rate Indicies for Turkey." Working Paper \#10/12: 1-16, Central Bank of Turkey, Ankara.

Sharpe, W.F. 1964. "Capital Asset Prices: A Theory of Market Equilibrium Under Conditions of Risk.” Journal of Finance 19, no. 3: 425-442.

Stattman, D. 1980. "Book Values and Stock Returns." Chicago MBA: A Journal of Selected Papers 4: $25-45$.

Sunder, S. 1980. "Stationarity of Market Risk: Random Coefficients Tests for Individual Stocks." Journal of Finance 35: 883-897. 